2019-06-01

\title{
Cross-Group Relationship Satisfaction: A Meta-Analysis
}

\author{
Elena Kelsey Henderson \\ Brigham Young University
}

Follow this and additional works at: https://scholarsarchive.byu.edu/etd

\section{BYU ScholarsArchive Citation}

Henderson, Elena Kelsey, "Cross-Group Relationship Satisfaction: A Meta-Analysis" (2019). Theses and Dissertations. 8477.

https://scholarsarchive.byu.edu/etd/8477

This Thesis is brought to you for free and open access by BYU ScholarsArchive. It has been accepted for inclusion in Theses and Dissertations by an authorized administrator of BYU ScholarsArchive. For more information, please contact scholarsarchive@byu.edu, ellen_amatangelo@byu.edu. 
Cross-Group Relationship Satisfaction: A Meta-Analysis

\author{
Elena Kelsey Henderson
}

A thesis submitted to the faculty of

Brigham Young University

in partial fulfillment of the requirements for the degree of

Master of Science

Scott Ronald Braithwaite, Chair

Scott A. Baldwin

Patrick R. Steffen

Department of Psychology

Brigham Young University

Copyright ( 2019 Elena Kelsey Henderson

All Rights Reserved 


\author{
ABSTRACT \\ Cross-Group Relationship Satisfaction: A Meta-Analysis \\ Elena Kelsey Henderson \\ Department of Psychology, BYU \\ Master of Science
}

Cross-group relationships are defined by romantic relationships involving two individuals from distinct racial or ethnic groups. For this paper, the terms "interethnic" and "interracial" are used as specifiers for the umbrella terms, "intergroup" and "cross-group." Studies examining whether cross-group romantic relationships are more or less satisfying than intergroup romantic relationships have yielded discrepant findings. Through a systematic review and meta-analysis of 27 studies, we found that there are no significant difference between cross-group and intergroup relationship satisfaction (aggregate $d=.024,95 \%$ CI $[-0.076 ; 0.123]$ ). Tests of moderation found that the amount of Asian participants included in individual studies on cross-group relationship satisfaction is significantly associated with effect size $d(\beta=.005, \mathrm{p}=.02 ; 95 \% \mathrm{CI}[.001 ; .008])$.

Keywords: marriage, couples, relationships, interracial, interethnic, cross-group, satisfaction 


\section{ACKNOWLEDGEMENTS}

I would like to thank Michael Henderson for inspiring me to work toward my goals regardless of life consequences. 
Table of Contents

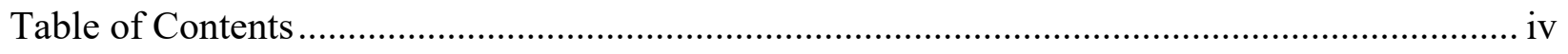

Cross-Group Relationship Satisfaction: A Meta-Analysis ...................................................... 1

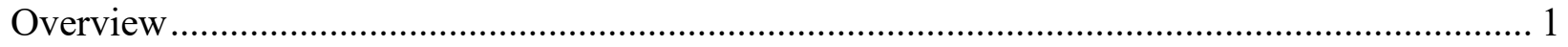



Attitudes Toward Cross-Group Couples ................................................................... 3

Intimate Relationship Theory and Cross-Group Relationships........................................... 4

Cross-Group Relationship Functioning....................................................................... 6

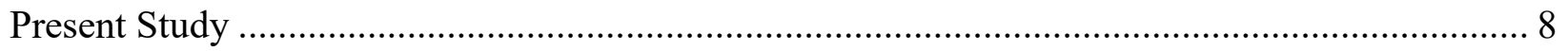



Data Collection and Extraction ............................................................................. 10

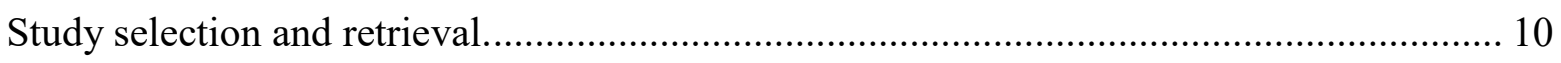

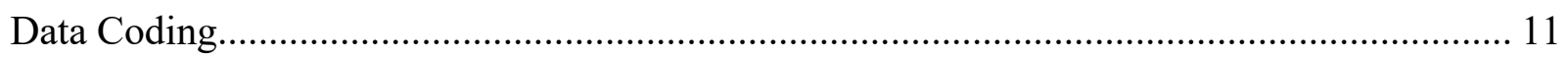

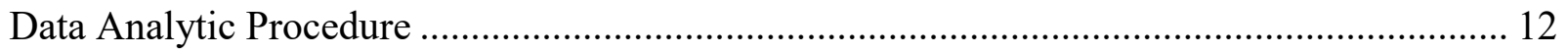

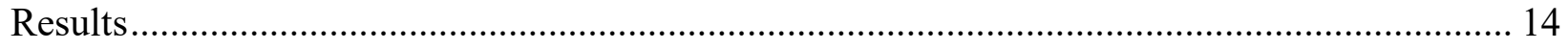

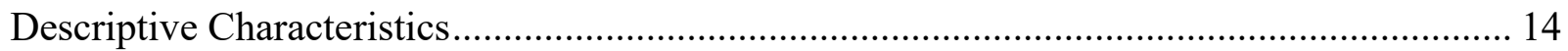

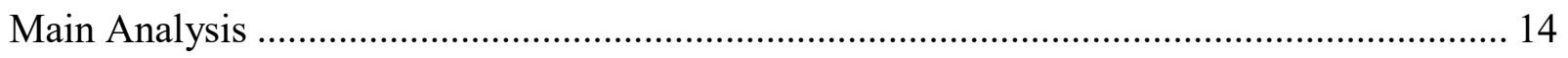

Is there a difference in relationship satisfaction in cross-group couples versus same-group

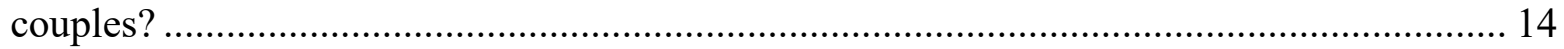

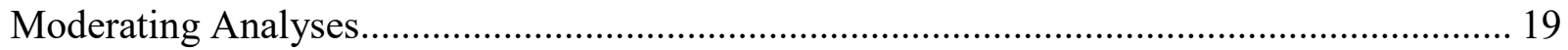

Do studies with more racially/ethnically diverse samples report greater difference in

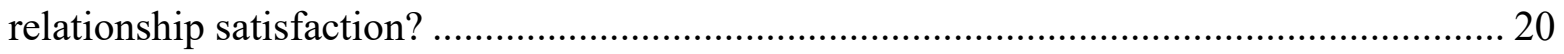

Does average length of relationship influence findings between studies? ........................ 23



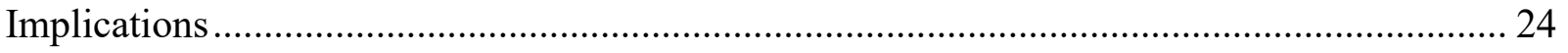

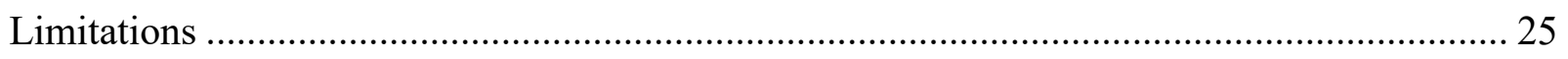



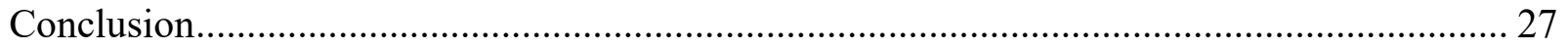

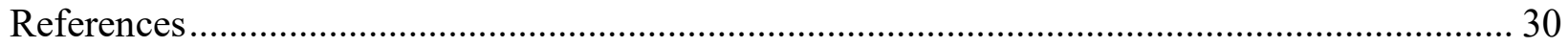




\section{Cross-Group Relationship Satisfaction: A Meta-Analysis}

\section{Overview}

The recent resurgence of nationalism in American politics reminds us that issues surrounding race and ethnicity continue to be relevant. As American society continues to become more diverse, it is important to understand the dynamics of romantic relationships between people from different racial and ethnic backgrounds. The term "race" is defined by the physical characteristics of an individual, like skin color (Merriam-Webster, 2019). The term "ethnicity" is defined by the cultural characteristics of an individual (e.g. Irish; American; Betancourt \& López, 1993). Thus, interracial couples are those that include individuals from different racial backgrounds and interethnic couples include individuals from different ethnic backgrounds. For this paper, the terms "intergroup" and "cross-group" will be used to describe interracial and interethnic couples. In this paper, we will use meta-analysis to examine whether individuals in cross-group couple experience higher or lower levels of satisfaction than intergroup couples.

The number of interracial unions in a geographic area is often used to measure social acceptance of racial minority groups by majority groups (Glazer, 1998; Lewis, Yancey, \& Beltzer, 1997; Yancey \& Yancey, 1998). Interracial marriage was punishable by law in many areas of the United States of America until the landmark civil rights decision of Loving $v$. Virginia that ended all racially based legal restrictions on marriage in 1967 (Loving v. Virginia, 1967). Since this ruling, interracial marriage in the United States has increased significantly. In $1970,2 \%$ of new marriages were interracial, increasing to $3.2 \%$ in 1980 , and then to $15 \%$ in 2010 (U.S. Census Bureau; 1970, 1980, 2010). Today, 8.4\% of total marriages in the United 
States are interracial (U.S. Census Bureau, 2015). In a 2015 analysis of U.S. Census Bureau data (2010), 17\% of newlyweds were married to someone of a difference race or ethnicity, and $14 \%$ of American infants were multiracial or multiethnic (Pew, 2015).

Attitudes toward interracial marriage have also changed in recent years. In 1994, 48\% of Americans approved of marriage between black and white individuals (Gallup, 2007). In 2013, $87 \%$ of Americans approved of interracial marriage (Gallup, 2013). Although cross-group marriages and their respective approval are increasing each year, these couples continue to face social challenges in response to their relationships (Bell \& Hastings, 2011; Field, Kimuna, \& Straus, 2013; Jackson, 2016). We review these challenges below in the context of theories about relationships and race/ethnicity.

\section{Intergroup Contact Theory}

Researchers have been studying interethnic and interracial interactions for decades (Allport, 1954; Wright, Aron, McLaughlin-Volpe, \& Ropp, 1997; Pettigrew, 1998). In 1954, American psychologist Gordon Allport developed the contact hypothesis, also known as Intergroup Contact Theory, which states that interpersonal contact is one of the best ways to reduce prejudice between majority and minority social groups. But his theory specifies that contact cannot have a positive effect if individuals experience anxiety during inter-group contact (Allport, 1954). Moreover, cross-group interaction might only be beneficial if social customs encourage egalitarian attitudes where groups engage in informal, personal interactions (Allport, 1954). More recent research expands this theory by showing that witnessing cross-group contact can improve attitudes toward the outgroup (Wright et al., 1997). In the context of this theory, inter-group marriage may be an important part of a multi-group society since marriage fosters 
informal, egalitarian contact between the extended families of those in cross-group romantic relationships.

\section{Attitudes Toward Cross-Group Couples}

Cross-group romantic relationships face many social challenges from both the majority and minority groups in the United States. A 1995 study found that many Black and White crossgroup couples experience social pressure to exemplify successful cross-group relationships and defend their relationships against racism or prejudice (Rosenblatt, Karis, \& Powell, 1995). In fact, some individuals are hesitant to engage in a cross-group romantic relationship because of this potential disapproval (Harris \& Kalbfleisch, 2000). Bell and Hastings (2011) found that Black-White interracial couples report threatening stares from friends and strangers as well as unkind comments about their relationship.

Social attitudes towards cross-group relationships are complex, with some racial/ethnic couples experiencing more disapproval than others. When comparing predominantly White universities with historically Black universities, Field et al. (2013) found that Black students disapproved of interracial dating more than White students. When responding to the statement "My parents think it is good for African Americans and Whites to date," 54.5\% of students at historically Black universities said their parents would disagree or strongly disagree with that statement. Forty-one percent of students from predominantly White universities also said that their parents would disagree or strongly disagree with that statement (Field et al., 2013). This is particularly concerning because, at both types of universities, students currently in same-race relationships reported the lowest level of approval for Black/White relationships (Field et al., 2013). 
However, students at both types of universities, reported higher approval of Asian/White relationships than Black/White relationships and had more favorable attitudes towards interracial dating than interracial marriage (i.e., $28.1 \%$ of students strongly agreed with Asian/White dating and $27.6 \%$ of students strongly agreed with Asian/White marriage; $27.4 \%$ students strongly agreed with Black/White dating and 25.8\% students strongly agreed with Black/White marriage; Field et al., 2013). These findings suggest that negative social attitudes toward cross-group relationships are present in American society and are likely a prevalent issue for cross-group couples, but that they differ for certain racial pairings (i.e., Asian individuals may be more accepted as interracial daters in the United States than Black individuals), indicating that the racial/ethnic makeup of each study's sample may yield distinct findings.

Jackson (2016) found that cross-group couples are often exposed to unique challenges that same-group couples do not typically encounter. These challenges predominantly fall into three categories: communication style — especially within couples who are multilingual—familial impression of the "out-group" partner (i.e., a partner who is not in their own racial/ethnic group), and societal discrimination of cross-group unions displayed through being ignored, receiving unwanted stares, or hearing offensive comments from strangers (Jackson, 2016). The challenges specific to cross-group couples raise questions about the degree to which cross-group couples differ when compared with same-group couples, and whether relationship satisfaction is implicated in these differences.

\section{Intimate Relationship Theory and Cross-Group Relationships}

An important theory that provides insight into cross-group relationships is the Vulnerability Stress Adaptation (VSA) model. The VSA model (Karney \& Bradbury, 1995) integrates previously established relationship theories to describe the longitudinal course of 
romantic relationships. This model posits that romantic relationships can be understood best when one understands the couple's vulnerabilities (e.g., attachment style, personality), stressors (e.g., socio-economic status, racism), and adaptive processes (communication skill, support provision, commitment). The VSA theory highlights the interrelationships between the various components of the model. For example, a couples' adaptive or maladaptive response to stress will either mitigate or increase their risk of instability. In the context of cross-group relationships, it is likely that perceptions of disapproval from family and society increase individual stress which could interact with spouses' personal vulnerabilities. This would create more stress if the perception of the partner from one group is insensitive to the concerns of the other partner. Depending on how they navigate these issues, their behavioral exchanges could lead to more commitment, strength and stability in the face of challenges or to deterioration (Karney \& Bradbury, 1995; Cohan \& Bradbury, 1997).

Given the clear distinctions in life experience among individuals from various racial/ethnic groups, it would seem that individuals in cross-group relationships might experience more stressors than intergroup relationships. La Taillade's (1999) examined this question and found that a major external stressor (i.e., discrimination) was not significantly related to the cross-group couples' relationship satisfaction. Although more research is needed to know whether this finding replicates, as well as to explore other potential moderators, it suggests that although perceptions of discrimination may not be associated with immediate decreases in relationship satisfaction. Understanding if and when cross-group couples do experience more or less relationship satisfaction is an important first step, however, before assessing what variables might predict differences for these couples. 


\section{Cross-Group Relationship Functioning}

Previous research has investigated the relationship between relationship satisfaction and marital instability (Karney \& Bradbury, 1995) and relationship functioning in cross-group marriage (Bratter \& King, 2008; Zhang \& Van Hook, 2009). Bratter and King (2008) used the 2002 National Survey of Family Growth to compare the likelihood of divorce of intraracial and interracial couples, and found that the percentage of couples divorcing in their tenth year of marriage was elevated in interracial unions compared to intraracial unions $(55 \%$ and $35.6 \%$, respectively); however, intraracial couples that had married before 1980 were more likely to divorce than interracial couples married in the same time frame (51.1\% and $46.3 \%$, respectively). Bratter and King (2008) also found that the racial makeup of the couples influenced divorce rates. Namely, couples made up of White females and non-White males were more likely to divorce than partnerships of White females and White males (e.g. Hispanic husband/White wife couples were 59\% more likely to divorce than White/White couples; Bratter \& King, 2008).

Further, Bratter and King (2008) found that couples made up of non-white females and white males and partnerships of Hispanic females and non-Hispanic males had similar or lower risks of divorce than couples made up of White males and White females (e.g. White husband/non-Hispanic Black wife couples were 44\% less likely to divorce than White/White couples). Further, Bratter and King (2008) found that marriages involving racially mixed women were $51 \%$ more likely to end in divorce than monoracial marriages, but couples involving racially mixed men were $60 \%$ less likely to end in divorce. These findings have indicated that, in general, non-White individuals who intermarry experienced less marital stability than individuals in same-race couples, though there is heterogeneity in relationship functioning regarding the racial/ethnic makeup of couples. 
Zhang and Van Hook (2009) examined marital instability in interracial marriage among White, Black, Hispanic, and Asian individuals by first examining differences in marital dissolution between groups and then by examining factors that elevate risk for divorce. Zhang and Van Hook's study (2009) found no significant differences in Hispanic/White couples and same-race couples in marital dissolution or dissolution risk factors. However, they found that couples made up of White women and non-White men were more likely to divorce than samerace couples. Zhang and Van Hook (2009) found the highest levels of marital instability in couples with Black husbands and White wives. These findings support those of Bratter and King (2008), indicating that the racial and ethnic combination of couples likely has influence over relationship satisfaction in gross-group couples. And again, these findings suggest that the diversity racial/ethnic makeup of study samples may have influence over results. These findings also speak to the complexity of race/ethnicity relations, namely that some racial groups may experience more positive outcomes in their interracial relationships than others, including social acceptance of their relationship, as Field et al. has found (2013).

Recent research has identified the complexity of comparing same-group (i.e. couples of the same race or ethnicity) and cross-group couples (i.e. couples of a different race or ethnicity). Hohmann-Marriott and Amato (2008) studied the factors underlying relationship quality between cross-group and same group couples. They found that people in cross-group unions reported lower levels of relationship quality than people in same-group unions, and that these differences were mediated by complex relationships histories, more heterogamous relationships, fewer shared values, and less support from parents (Hohmann-Marriott \&Amato, 2008). Some researchers have asserted that the current methods of exploring cross-group relationship quality 
are insufficient, and that the role of racial identity in cross-group relationships should be explored in future research (Afful, Wohlford, \& Stoelting, 2015).

\section{Present Study}

After decades of research on the relationship between race/ethnicity on relationship satisfaction, there appears to be two general findings on this topic within the field. On one hand, research suggests that individuals in cross-group relationships report lower levels of relationship satisfaction than individuals in same-group relationships (Hohmann-Marriott \& Amato, 2008; Bratter \& King, 2008). Opposing research suggests that cross-group relationships are no more difficult to maintain than same-group relationships (Dainton, 2015; Troy et al., 2006), and that couples in cross-group relationships report higher levels of relationship satisfaction than those in same-group relationships (Zhang \& Van Hook, 2009; Troy, Lewis-Smith, \& Laurenceau, 2006; Negy \& Snyder, 2000).

Because American attitudes toward cross-group relationships have changed significantly in the past 24 years, we aim to summarize the existing research on cross-group relationships and examine potential trends over time and moderators of outcomes. The first topic of interest in our study is the inconsistency of findings across studies regarding relationship satisfaction in crossgroup couples compared to same-group couples. The second topic of interest for our study is the demographic characteristics of each sample. This would help understand some of the inconsistencies in prior research, namely whether the racial/ethnic makeup of participants influence whether a difference in relationship satisfaction is observed between cross-group and same-group couples. Lastly, prior research has found differences in relationship functioning contingent on date of being married and relationship length (i.e., divorce being higher if the couple was married before 1980 or in their tenth year of marriage; Bratter \& King, 2008). 
Further, Bratter and King's (2008) findings of relationship length and relationship satisfaction were inconsistent across individual racial/ethnic makeup of couple, so we want to see if this finding relates to the results of other studies. So, this study is designed to address four questions regarding relationship quality in cross-group relationships: (1) Is there a difference in relationship satisfaction among cross-group couples versus same-group couples? (2) Does the racial/ethnic makeup of study sample influence findings? (3) Does average length of relationship influence findings between studies? (4) Do demographic variables and date of study moderate the findings of the included studies?

\section{Method}

Due to the various results between studies about this topic, we conducted a systematic review and meta-analysis to synthesize the results of related studies and identify the aggregated effect size between them (i.e., Cohen's $d=$ differences in relationship satisfaction between crossgroup and same-group relationship satisfaction). Published and unpublished studies examining the relationship between intragroup and cross-group relationship satisfaction were included in this meta-analysis. Basic criteria for inclusion were that the study was written in English, conducted in the USA, and assessed both same-group and cross-group relationship satisfaction. When studies involved other questions related to cross-group and same-group relationship functioning, we analyzed only the data regarding relationship satisfaction.

The systematic review and meta-analysis were conducted and reported in accordance to PRISMA guidelines (Moher, Liberati, Tetzlaff, \& Altman, 2009), the Cochrane Handbook for Systematic Review of Interventions (version 5.1; Cochrane, 2011), and a published guide to conducting meta-analyses (Borenstein, Hedges, Higgins, \& Rothstein, 2009). To investigate research question 1, the findings of prior studies about relationship satisfaction of cross-group 
couples and same-group couples were aggregated in an excel spreadsheet, organized by number of participants in same-group couples, cross-group couples, relationship satisfaction measure, reported relationship satisfaction score, and reported effect size. Reported effect sizes $d$ were directly coded in our Excel spreadsheet. Other reported effect sizes (e.g., $F$-scores) were transformed to Cohen's $d$ values to properly be included in our analysis (Borenstein, Hedges, Higgins, \& Rothstein, 2009).

After the data was extracted, it was analyzed (STATA command: "metan") to compute the summary effect size of Cohen's $d$, where Cohen's $d$ indicates the difference between relationship satisfaction of cross-group couples compared to same-group couples). To investigate research questions 2-4, the demographic characteristics (i.e., race/ethnicity, average age and education level of men and women, and average relationship length in years) of each sample were coded accordingly (e.g., coding the percentage of racial/ethnic participants for each study sample with decimal equivalents). Data were later analyzed in a regression with each study's precalculated effect size regarding cross-group relationship satisfaction compared to same-group relationship satisfaction.

\section{Data Collection and Extraction}

Study selection and retrieval. For this meta-analysis, we selected studies that provide findings about relationship satisfaction between cross-group couples and same-group couples. To identify fit studies, we used electronic databases (EBSCO, Elsevier, ProQuest, PsycINFO and SCOPUS) to search for studies that used keywords related to cross-group and same-group relationship satisfaction: “cross-group," “interracial," “interethnic," “multiracial,” or "multicultural"; "relationship" "marital" or "couple"; and "satisfaction," "happiness," or "quality," in comparison to "same-group," "intraracial," "intra-ethnic," or "intracultural" 
couples. we accessed these databases primarily through Brigham Young University's library website and Google Scholar.

We collected data from 27 studies that met inclusion criteria: (1) Samples from United States of America, (2) studies that primarily compare romantic relationship satisfaction between cross-group and same-group couples within the study, (3) studies that included demographic information regarding the sample's race/ethnicity, and (4) studies that provided information regarding at least one of the following: average relationship length, age and education for the sample. Data was excluded from studies that met exclusion criteria: (1) studies conducted in countries other than United States of America, (2) studies that were written in a language other than English, and (3) studies that did not provide enough information to identify the resulting effect sizes of the conducted research.

To control for the risk of publication bias, we included published studies and unpublished theses and dissertations in the meta-analysis. Further, we tested for publication bias in Stata, using funnel plots and the trim-and-fill procedure (version 15; commands "metafunnel" and “metatrim").

\section{Data Coding}

Across all studies, we coded variables related to number of participants in cross-group relationships, the number of participants in same-group relationships, the relationship satisfaction measure used and average individual/couple scores, data analytic procedure and reported effect size, racial/ethnic demographic information (number of participants of Hispanic, Asian, Black, White, and Other race/ethnicity), average age and education of men and women in the sample, and average relationship length in years. Information obtained from the studies was extracted directly from the documents, reducing the likelihood of coding error. Coding inconsistencies 
were planned to be resolved through direct examination of the respective studies. No coding inconsistencies occurred. One study was mistakenly coded two times and the duplicate code was removed from the dataset as soon as the error was noticed.

\section{Data Analytic Procedure}

We systematically reviewed 27 studies that met the inclusion criteria. Studies that featured individual scores and couple scores were included, resulting in a total sample of 14,660 individuals/couples (individuals/couples in same-group relationships $n=12,765$;

individuals/couples in cross-group relationships $n=3673$ ). These studies varied in their statistical procedures and reported effect sizes (e.g., log odds ratio and $d$ ). We converted non-Cohen's $d$ effect sizes to Cohen's $d$ values to best include each study (Borenstein, Hedges, Higgins, \& Rothstein, 2009). We then calculated their respective standard errors and used these precalculated effect estimates for the meta-analysis in Stata (version 15.0; command "metan"; Harris, Bradburn, Deeks, Harbord, Altman, \& Sterne, 2008).

We conducted a sensitivity analysis for all types of missing data. Regarding our primary research question, we assessed missing data of study-reported standard error through pairwise correlations of missing values. We found this missingness to be insignificantly correlated with our precalculated effect size Cohen's $d(r=-0.01)$. This suggests that studies that did not report the standard error — nor the necessary values to compute standard error-would have no significant effect on the meta-analysis of studies with complete data. Next, we assessed for missingness in our moderating variables. We found that the demographic characteristics and average relationship length of participants were generally insignificantly correlated with other variables. However, there were some special cases. Studies with missing data regarding the education level of male participants showed a moderate correlation between this and the 
percentage of white participants $(r=-.44)$, the mean age of male participants $(r=-.52)$ and the mean age of female participants $(r=-.50)$. We had similar findings regarding missing data about the education level of female participants, with moderate correlations between this and the percentage of white participants $(r=-.44)$, the mean age of male participants $(r=-.50)$, the mean age of female participants $(r=-.52)$, and mean relationship length $(r=-.46)$. The results of these analyses indicate that there are some influences of missing data between moderating variables and should be interpreted with caution. In accordance with the guidelines of Cochrane (2011), we decided to include relevant studies as the inclusion of such results outweigh the potential concerns of the moderating variables.

We attempted contact with all authors who produced studies with missing data via email, specifying our deadline for correspondence. We reached out to authors of 18 studies and received a response regarding 9 of those. Of the responses, one researcher shared data with us, and eight informed us that original data was inaccessible. Missing data was replaced with the mean value of their respective data type, in accordance with previous guidelines (Cochrane, 2011). The $I^{2}$ value was used to assess for the total variation across studies due to heterogeneity rather than chance. After the meta-analysis was conducted, we conducted a meta-regression to explore contributing factors to between-study heterogeneity. We regressed each study's calculated $d$ value with demographic characteristics (i.e., racial/ethnic makeup, age, and education level) and average relationship length in years to assess for contributions to heterogeneity. 


\section{Results}

\section{Descriptive Characteristics}

We extracted data and effect sizes from 27 studies examining the relationship between relationship satisfaction among cross-group and same-group couples. Studies that utilized one score per couple reported participants in terms of couples (i.e., 1 couple $=1 \mathrm{~N}$ ) were aggregated with studies that reported individual scores in order to best represent data that met inclusion criteria and not inflate reported sample sizes. The total number of individuals and couples represented across all studies was 14,400, with 12,561 representing individuals/couples in samegroup relationships and 3617 individuals/couples in cross-group relationships. The average age of female participants was 29.1 years old, and the average age of male participants was 29.9 years old. The average racial/ethnic composition of study sample was $43.9 \%$ White, $21.1 \%$ Asian, 17.5\% Hispanic, 12\% Black, and 5.3\% other non-White race/ethnicity.

\section{Main Analysis}

Is there a difference in relationship satisfaction in cross-group couples versus samegroup couples?

Across all 27 studies, the random-effects weighted-average effect size was $d=.02$ with a $95 \%$ confidence interval of $d=-0.08$ to $d=0.12$, with $d$ representing the difference in relationship satisfaction between same-group and cross-group couples, with positive values indicating more relationship satisfaction within cross-group couples than in same-group couples. Effect size estimates ranged from $d=-0.45$ to $d=0.71$ (See Table 1 and Figure 1). These results indicate that, when aggregating the results of 27 studies, there is no significant difference in relationship satisfaction among cross-group couples compared to relationship satisfaction among same-group couples. These estimates demonstrated significant heterogeneity between studies $(Q$ 
$\left.=224.07, p<0.001 ; I^{2}=88.4 \%\right)$. This high heterogeneity indicates that the variability between included effect sizes was greater than expected from chance alone. In accordance with previous guidelines, we conducted additional analyses to determine moderating variables for the heterogeneity (Cochrane, 2011).

\section{Table 1}

Results from Random Effects Meta-Analysis by Precalculated Effect Estimates

\begin{tabular}{|c|c|c|c|c|}
\hline Study & Effect Size $d$ & $\begin{array}{c}\text { 95\% Confidence } \\
\text { Interval LL }\end{array}$ & $\begin{array}{c}\text { 95\% Confidence } \\
\text { Interval UL }\end{array}$ & $\%$ Weight of Study \\
\hline Canlas & 0.013 & -.024 & .050 & 11.12 \\
\hline Asidao & -0.413 & -.506 & -.320 & 10.27 \\
\hline Chan & 0.155 & -1.615 & 1.925 & 0.31 \\
\hline Direso & 0.353 & .097 & .609 & 6.46 \\
\hline $\mathrm{Fu}$ & -0.030 & -.147 & .087 & 9.77 \\
\hline Galloway & 0.020 & -.842 & .882 & 1.19 \\
\hline Garrett & -0.051 & -1.318 & 1.216 & .59 \\
\hline Guner & -0.454 & -2.825 & 1.917 & 0.17 \\
\hline Gurung & -0.054 & -.148 & .040 & 10.25 \\
\hline Herr & -0.131 & -1.436 & 1.174 & 0.55 \\
\hline Hohmann- & 0.250 & -0.612 & 1.112 & 1.19 \\
\hline \multicolumn{5}{|l|}{ Marriott } \\
\hline Study 1 & & & & \\
\hline
\end{tabular}


Hohmann-

0.250

$-0.612$

1.112

1.19

Marriott

Study 2

Jansezian

$-0.500$

$-1.362$

0.362

1.19

Johns,

0.033

$-3.083$

3.149

0.10

Newcomb,

and Bradury

\begin{tabular}{|c|c|c|c|c|}
\hline Kohn & -0.169 & -1.241 & .903 & 0.80 \\
\hline La Talliade & -0.155 & -2.853 & 2.543 & 0.13 \\
\hline Lande & 0.117 & .106 & .128 & 11.27 \\
\hline Lantsman & 0.284 & -.757 & 1.325 & .85 \\
\hline Lee & 0.027 & -1.498 & 1.552 & .41 \\
\hline Muller & -0.106 & -.671 & .459 & 2.43 \\
\hline Naratadam & 0.709 & -.158 & 1.576 & 1.18 \\
\hline Negy \& & -0.051 & -2.029 & 1.927 & 0.25 \\
\hline \multicolumn{5}{|l|}{ Snyder } \\
\hline Reiter & -0.226 & -1.088 & .636 & 1.19 \\
\hline Shibazaki & -0.172 & -.274 & -0.070 & 10.09 \\
\hline Stevenson & -0.069 & -1.181 & 1.043 & 0.75 \\
\hline
\end{tabular}


Troy, Lewis,

0.479

.330

.628

9.01

\&

Laurenceau

$\mathrm{Wu}$

0.125

$-.095$

.345

7.29

\begin{tabular}{|c|c|c|c|c|}
\hline Pooled ES & 0.024 & -0.076 & 0.123 & 100.00 \\
\hline
\end{tabular}

Heterogeneity $\chi^{2}(26)=224.07, p<.001, I^{2}=88.4 \%$

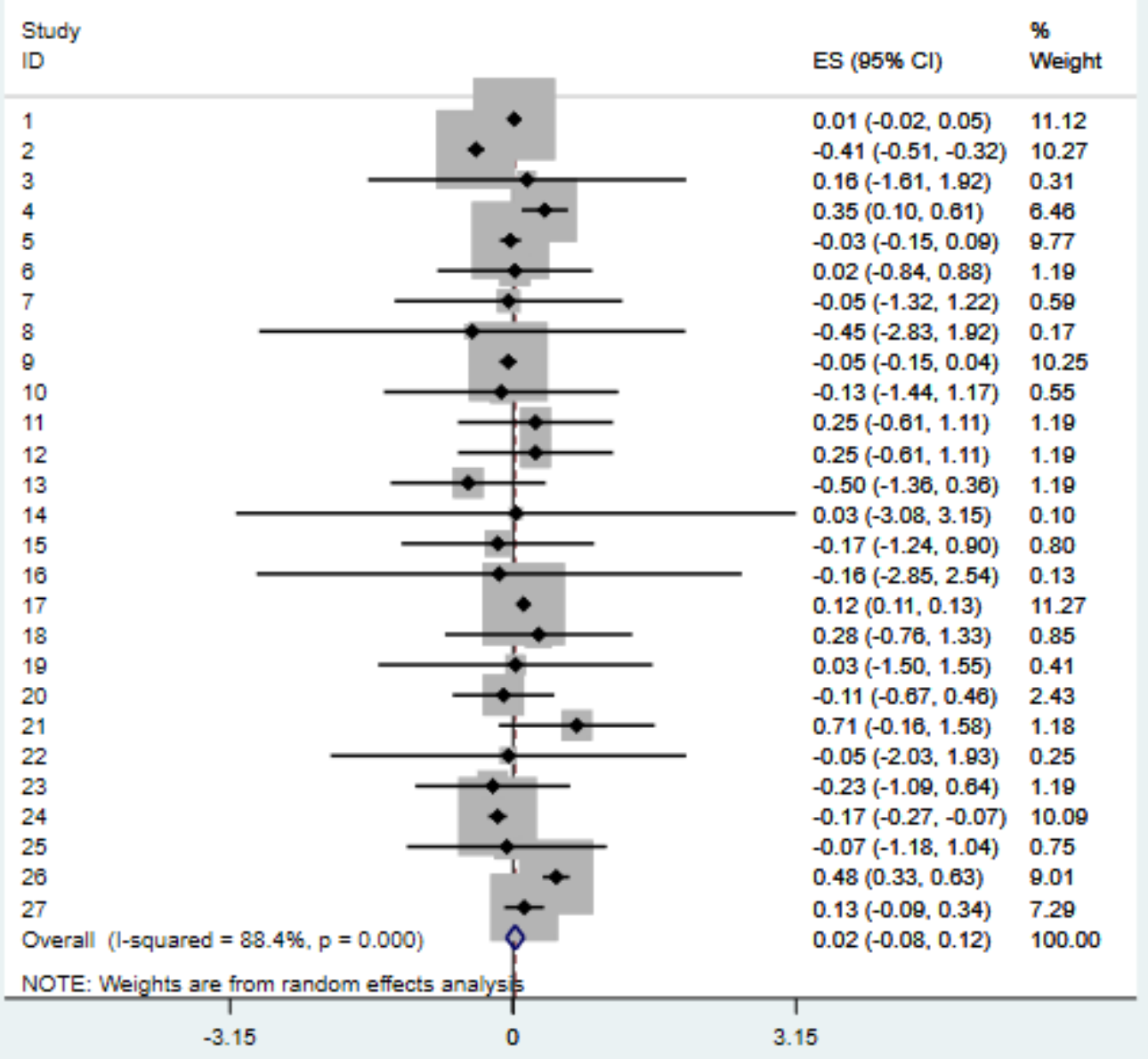

Figure 1. Forest plot displaying an inverse-variance weighted random-effects meta-analysis of the difference in relationship satisfaction between cross-group and same-group couples. 
To explain the high heterogeneity between effect size estimates, we conducted a metaregression in Stata (command "metareg"). We explored demographic characteristics of each sample, including racial/ethnic makeup of each sample (coded as the decimal approximation of the proportion of individual participants from various racial/ethnic background as distinct variables making up each study's sample), the average age and education of participants (coded as number of respective years), and the average length of romantic relationships (coded in years). The results of the meta-regression indicated that the demographic variables of each study explained approximately $45 \%$ of the between-study variance (Residual $I^{2}=43.54 \%$ ).

We assessed for publication bias using a funnel plot in Stata (command "metafunnel"). The funnel plot did not show substantial asymmetry, suggesting that our estimated effect sizes were not significantly impacted by publication bias (See Figure 2). We performed the trim and fill procedure (command "metatrim") to further test and adjust our data for possible publication bias. No estimated fill points were produced from this analysis. The results of this procedure indicated that there was no significant evidence of publication bias impacting the results of this meta-analysis. 


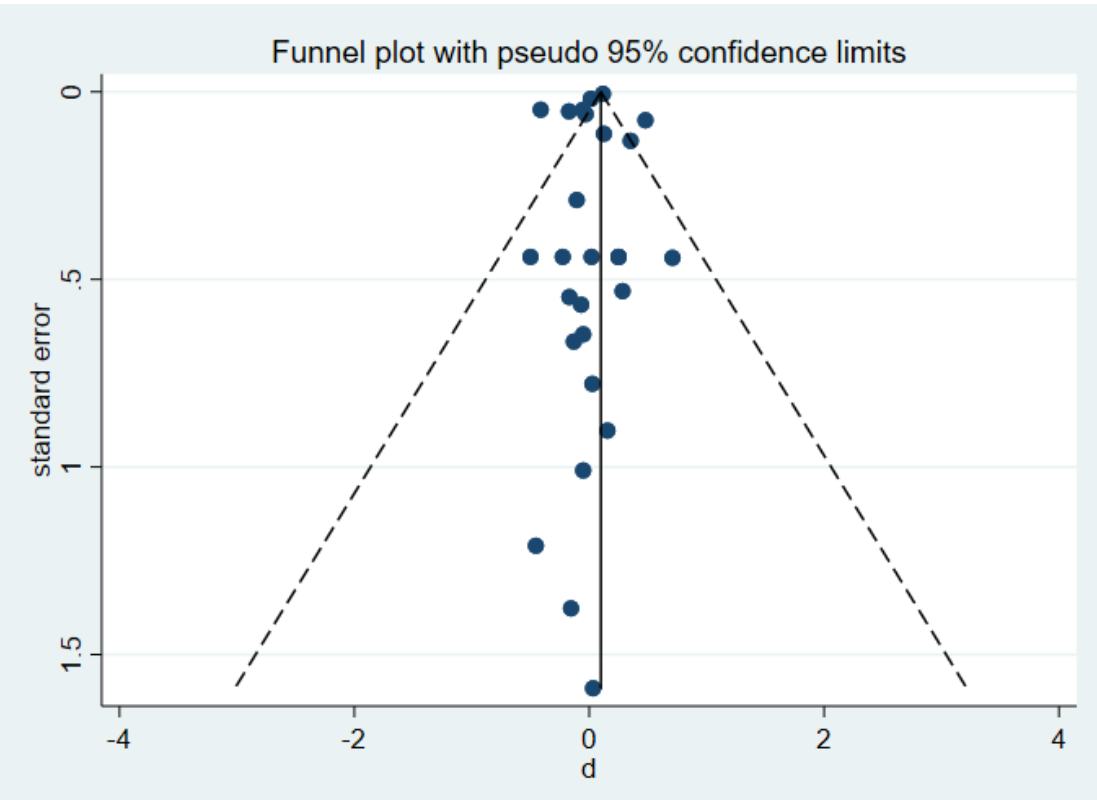

Figure 2. Funnel plot of random-effects meta-analysis. This figure illustrates the low risk of publication bias influencing our findings.

\section{Moderating Analyses}

We conducted a meta-regression to assess for moderating variables of our meta-analysis. Our moderating variables included mean age and education of participants. We found that there were no significant relationships between the mean age of male and female participants and effect size $d(\beta<.001, p=.99 ; 95 \%$ CI $[-.19 ; .19]$ and $\beta=.005, p=.95 ; 95 \%$ CI $[-.19 ; .20]$, respectively). Regarding education level, we found that there is no significant relationship between the mean education level of male and female participants and reported effect size $d(\beta=$ $.14, p=.78 ; 95 \%$ CI $[-.88 ; 1.15]$ and $\beta=-.03, p=.95 ; 95 \%$ CI $[-.96 ; .91]$, respectively). This suggests that there is no significant effect of the participant age or education level on observed differences between same-group and cross-group couple satisfaction.

In line with America's history of changing cross-group attitudes, we also assessed for the date of the study as a moderating variable. Study dates ranged from 1994 to 2013 . The results 
of this analysis found that there is no significant relationship between the date of the study and the reported effect size $d(\beta=.01, p=.47 ; 95 \%$ CI $[-.03 ; .06])$. This suggests that the date of the study does not have an effect on the results of studies that identify differences between crossgroup and same-group relationship satisfaction.

\section{Do studies with more racially/ethnically diverse samples report greater difference in} relationship satisfaction?

In order to determine the influence of racial/ethnic makeup of samples and effect size, we conducted a regression analyses between each study's effect size and the proportion of individual participants from various racial/ethnic groups such as White, Black, Hispanic, Asian, and nonWhite other race/ethnicity (coded as individual variables in the dataset, e.g., "prcntblack" and "prentwhite"). Correlational analyses indicated that the difference in cross-group relationship satisfaction and same-group relationship satisfaction with the proportion of various racial/ethnic participants were weakly to moderately correlated (see Table 2).

Regression results indicated that the proportion of White participants in a study did not have a significant effect on effect size $d(\beta=-.004, p=.65 ; 95 \%$ CI $[-.02 ; .01])$. Further, results of this analysis indicated that neither the proportion of Black, Hispanic, nor other racial/ethnic participants in a study has a significant influence on effect size $(\beta=.002, p=.88 ; 95 \%$ CI [-.02; $.02] ; \beta=.002, p=.78 ; 95 \%$ CI $[-.02 ; .02]$; and $\beta=-.002, p=.89 ; 95 \%$ CI $[-.03 ; .02]$, respectively). This suggests that the proportion of various racial and ethnic groups do not significantly affect the difference between relationship satisfaction between same-group and cross-group couples.

Correlation results for the proportion of Asian participants in a sample on reported effect size indicated that there is a significant relationship between reported effect size $d$ and the 
percentage of Asian participants $(r=.45$; see Table 2$)$. Upon conducting a regression to explore this relationship, we found a small, although significant relationship between these variables, that with every 1 percent increase in Asian participants, effect size $d$ increased by $.005(\beta=.005, p=$ $.02 ; 95 \% \mathrm{CI}[.001 ; .008])$. This suggests that increased proportion of Asian participants marginally increases reported differences between relationship satisfaction among cross-group couples compared to that of same-group couples. 
Table 2

Correlation Matrix of Cohen's $d$ and Demographic Variables






\section{Does average length of relationship influence findings between studies?}

We conducted a regression to assess the relationship between the average relationship length of participants (in years) and effect size estimates. Results for this analysis suggest that there is no significant relationship between the average length of time that sample couples have been together and the reported difference between cross-group and same-group relationship satisfaction $(\beta=-.02, p=.64 ; 95 \%$ CI $[-.09 ; .06])$.

\section{Discussion}

We conducted a meta-analysis $(k=27)$ comparing the findings of relationship satisfaction among same-group (i.e., individuals of same-race/same-ethnicity) couples compared to that of cross-group couples (i.e., individuals of different race/different ethnicity). Results of this analysis indicated that there is no significant difference between relationship satisfaction between these two groups. This was consistent with our initial hypothesis, formed from the inconsistent findings of prior research.

We found that the racial/ethnic makeup of a study sample was somewhat correlated with study effect size, however regression analyses indicated that the only statistically significant racial/ethnic influence on effect size was the proportion of Asian participants in a sample, noting a slight increase in effect size with increased number of Asian participants. This may be explained by a few things. There is a general lower risk of divorce among Asian people (Zhang \& Van Hook, 2009), so this may increase some of the significant findings of prior research that sees greater relationship instability in either same-group or cross-group couples (i.e. BlackWhite couples vs same-race Black or White couples, Bratter and King, 2008). Further, several studies included Asian participants in the "Other" racial/ethnic category, where others featured only couples with at least one partner being of Asian descent. It is important to note that racial 
ethnic groups (i.e., Black, Hispanic, White) were consistently represented as their own groups in other studies. Further, Asian individuals involved in same-group relationships may vary from those in cross-group relationships. Asian individuals who enter an interracial marriage are more likely to be marrying for a second time and show more assimilation to American culture than Asian individuals in intraracial relationships, suggesting that individuals of Asian descent may have particular individual characteristics when involved in interracial relationships, and are best not being categorized with other racial/ethnic groups because of their complexity (Chan, 1997).

Lastly, we found that, although weakly negatively correlated, there was no significant influence of the average relationship length in years on effect size $d$. This suggests that the average relationship length of the sample did not significantly affect differences in reported relationship satisfaction between same-groups and cross-group couples. This finding might be explained by our decision to take the average length of the total sample, rather than comparing the average length per group and comparing them separately to the effect size $d$, or the average couple relationship satisfaction score. Such analyses seemed beyond the scope of this project, in which we did not control for distinct relationship measures or racial/ethnic subgroup analyses, so we took the average for ease of interpretation. However, future research may benefit from analyzing this question at the study level.

\section{Implications}

The results of our study indicate that there are no significant differences in relationship satisfaction of cross-group couples and same-group couples. This suggests that individuals from various racial/ethnic backgrounds will probably not experience greater or worse relationship functioning by dating outside of their respective racial/ethnic group, potentially refuting social exchange theory of interracial romantic relationships (Lewis et al, 1997). It would be interesting 
for future studies to assess this topic further and explore the social capital of individuals of crossgroup couples in which both partners are from different minority populations and compare them with same-group couples of majority populations and minority populations.

Results of our study lend credibility to the vulnerability-stress-adaptation (VSA) model (Karney \& Bradbury, 1995). While prior research has categorized participants and relationship type to assess for differences in relationship functioning in two groups, the aggregate of these findings shows this to be problematic. Karney and Bradbury's (1995) model is appropriate for discussing cross-group relationship functioning due to the emphasis on the individual complexity and how people bring their vulnerabilities and characteristics into a relationship. Our study found that that relationship satisfaction in both same-group and cross-group couples is rooted in individual differences between couples. In agreement with VSA theory, our study supports the notion that the individual characteristics of people in romantic relationships holds more influence on relationship satisfaction and stability than simply one characteristic (i.e., their racial/ethnic background).

\section{Limitations}

Our study has limitations. The first of which is that our heterogeneity estimates were much higher than expected due to chance alone. Preliminary analyses found considerable heterogeneity of our studies $(88 \%)$. This initial estimate suggests that there is considerable risk of error in combining the studies. In accordance with previous guidelines (Cochrane, 2011), we made the decision to explore and explain the heterogeneity and run a random-effects metaanalysis for the data rather than conduct a systemic review. A meta-regression of contributing variables explained approximately $40 \%$ of the between-study variance, so we had a residual heterogeneity estimate of $48.92 \%$, allowing our data to fall into the acceptable range of moderate 
heterogeneity (Cochrane, 2011). Although we were able to explain a significant amount of between-study heterogeneity, we did not reach the $<40 \%$ threshold of heterogeneity that would classify the variance as trivial (Cochrane, 2011).

Overall, the results of our study suggest that there is no significant difference in relationship satisfaction between cross-group and same-group couples. However, our study only took into account studies that were conducted in the United States, limiting our conclusions to an American sample. Further, our study examined the proportion of various racial/ethnic groups in the sample of each study. For ease of interpretation of our research questions (namely, "is there a difference between relationship satisfaction between same-group and cross-group couples?"), we utilized two major groups: same-group couples and cross-group couples and moderated by racial/ethnic makeup of each sample. It would be interesting for future research to identify whether there are differences at the individual racial/ethnic makeup of each couple, perhaps synthesizing results from studies strictly looking at Black-White couples, for example. While this question was beyond the scope of this project, our results may prove useful as preliminary findings for future research. Such research would benefit the field in identifying any difference between the findings related to the racial/ethnic type of same-group and cross-group relationship satisfaction.

The results of our study found that relationship length did not significantly affect study effect size between same-group and cross-group couple satisfaction. One limitation of this measure was that we measured the average relationship length of the sample, rather than compare the average relationship length of the respective groups. Not all studies separated the average relationship length by group, rather they reported the average relationship length of the sample. We continued to use such data to include as many qualifying studies in our analysis 
available (Cochrane, 2011). Still, this limits our generalizability of the finding that relationship length is not an indicator of significant difference between same-group and cross-group relationship satisfaction.

\section{Future Research}

The results of this study found that there is no significant difference between relationship satisfaction among same-group and cross-group couples. Still, our study had limitations. These limitations resulted largely from inconsistent reporting practices in the field. Given the limitations of our study, we suggest that future research expand to international sources and identify possible differences in relationship satisfaction among couples around the world. Further, future research may benefit from utilizing resources that identify specific racial/ethnic makeup of individuals in romantic relationships and the unique experiences they bring to a romantic relationship. Moreover, future research would benefit from further identifying social challenges the cross-group couples face and possible difference between those of same-group couples. It would also be interesting to see future research identify more details about the dissolution of cross-group couples compared to same-group couples to better understand the relationship between relationship satisfaction and relationship stability according to a longitudinal model such as the VSA approach (Karney \& Bradbury, 1995). Lastly, we encourage future research to include transparent, inclusive reporting in their research, so it may be better utilized in the field of meta-analytic psychological research.

\section{Conclusion}

Prior research has identified the inconsistency of findings related to cross-group and this study aimed to better explain these inconsistencies. Prior research has sought to identify differences in romantic relationship functioning in cross-group couples, namely relationship 
satisfaction compared to that in same-group couples. The present study aggregated and analyzed the various findings of relationship satisfaction and the racial/ethnic presence in relationship research. Our findings suggest that there is no significant difference in relationship satisfaction between groups; however, we had several limitations including a moderately heterogenous sample and a lack of subgroup analyses.

Still, our findings indicate that cross-group romantic relationships are complex and are no more or less likely to be satisfactory than same-group romantic relationships. Our findings have implications for social exchange theory, in that there does not appear to be gain in the sense of relationship satisfaction when comparing these relationships. Our findings are consistent with the vulnerability-stress-adaptation (VSA) theory of relationship stability, in that the complexities of individuals and how they respond to stress ultimately impact their relationship, rather than one characteristic determining the success of a couple.

Lastly, we found that, in general, demographic characteristics of a study's sample, including the racial/ethnic makeup of participants, has no significant effect on the reported effect size (i.e., difference in relationship satisfaction). This suggests that individuals in romantic relationships are more complex than their demographic backgrounds, and that relationship satisfaction of an individual or couples is likely related to factors other than these. Our findings strongly suggest that cross-group relationships are no different in relationship satisfaction than same-group relationships, however they remain in the minority of couples. As the number of cross-group unions in an area is often used to measure social acceptance and the USA has seen a steady increase in such unions (Glazer, 1998; Lewis, Yancey, \& Beltzer, 1997; Yancey \& Yancey, 1998), it would be beneficial to assess individual and couple functioning of individuals in such relationships along with attitudes of other people toward cross-group relationships. 
Given their relevance to social issues, it is essential that research on cross-group relations continues to be conducted. 


\section{References}

Afful, S., Wohlford, C., Stoelting, S. M. (2015). Beyond "difference": Examining the process and flexibility of racial identity in interracial marriages. Journal of Social Issues, 71(4), 659-674. doi:10.1111/josi.1214

Allport, G.W. (1954). The nature of prejudice. Cambridge, MA: Perseus Books

Asidao, C. S. (2002). Exploring variables associated with interracial and intraracial couples' relationship sastisfaction (Thesis). Retrieved from Proquest Theses and Dissertations (Accsession No. 3044044).*

Bell, G. C., Hastings, S. O. (2011). Black and white interracial couples: Managing relational disapproval through facework. Howard Journal of Communications, 22(3), 240-259. doi:10.1080/10646175.2011.590405

Betancourt, H., Lopez, S. R. (1993). The study of culture, ethnicity, and race in American psychology. American Psychologist, 48(6), 629-637. doi: 10.1037/0003-066X.48.6.629

Borenstein, M., Hedges, L. V., Higgins, J. P. T., Rothstein, H. R. (2009). Introduction to metaanalysis. Chichester: John Wiley \& Sons, Ltd.

Bratter, J. L., King, R. B. (2008). “But will it last?”: Marital instability among interracial and same-race couples. Family Relations, 57(2), 160-171. doi:10.1111/j.17413729.2008.00491.x

Canlas, J. M. (2012). Relational and social contexts as predictors of satisfaction and stability among Asian-White couples (Doctoral dissertation). Retrieved from Brigham Young University Scholars Archive (Accession No. 3232).* 
Chan, A. Y. (1997). A comparison of the marital quality of Asian-White couples to that of same-race White couples (Doctoral dissertation). Retrieved from Proquest Theses and Dissertations Database (Accession No. 9804990).*

Cohan, C. L., \& Bradbury, T. N. (1997). Negative life events, marital interaction, and the longitudinal course of newlywed marriage. Journal of Personality and Social Psychology, 73(1), 114.

Cochrane Collaboration (2011). Cochrane handbook for systematic reviews of interventions version 5.1.0. Retrieved from http://handbook.cochrane.org/

Dainton, M. (2015). An interdependence approach to relationship maintenance in interracial marriage. Journal of Social Issues, 61(4), 772-787. doi: 10.1111/josi.12148

Direso, S. A., (2008). Commitment processes in interracial and intraracial romantic relationships: An extension of the investment model (Doctoral dissertation). Retrieved from Proquest Theses and Dissertations Database (Accession No. 3329795).*

Field, C. J., Kimuna, S. R., Straus, M. A. (2013). Attitudes toward interracial relationships among college students: Race, class, gender, and perceptions of parental views. Journal of Black Studies, 44(7) - 741-776. doi: 10.11770021934713507580

Fu, X., Tora, J., \& Kendall, H. (2001). Marital happiness and inter-racial marriage: A study in a multi-ethnic community in Hawaii. Journal of Comparative Family Studies, 32(1), 47.*

Galloway, S. C. (2011). Mexican American women in couple relationships: A comparison of intra-ethnic and interethnic couples (Doctoral dissertation). Retrieved from Proquest Theses and Dissertations (Accession No. 3467160).* 
Gallup Poll. (2007). "Do you approve or disapprove of marriage between blacks and whites?” June 4-24, 2007. Retrieved from https://news.gallup.com/poll/28417/most-americansapprove-interracial-marriages.aspx

Gallup Poll. (2013). “Do you approve or disapprove of marriage between blacks and whites?” June 13 - July 5, 2013. Retrieved from https://news.gallup.com/poll/163697/approvemarriage-blacks-whites.aspx

Garrett, J. W. (2004). The marital satisfaction of Hispanic-White interracial couples (Doctoral dissertation). Retrieved from Proquest Theses and Dissertations (Accession No. 3154239)**

Glazer, N. (1998). We are all multiculturalists now. Cambridge, MA: Harvard University Press.

Guner, G. (1999). Value similarity and marital satisfaction among interracially and intraracially married couples (Doctoral dissertation). Retrieved from Proquest Theses and Dissertations (Accession No. 9975617).*

Gurung, R. A. R. \& Duong, T. Mixing and matching: Assessing the concomitants of mixedethnic relationships. Journal of Social and Personal Relationships, 16(5), 639-657.*

Harris, R. J., Bradburn, M. J., Deeks, J. J., Harbord, R. M., Altman, D. G., \& Sterne, J. A. (2008). Metan: fixed- and random-effects meta-analysis. The Stata Journal, 8(1), 3-28.

Harris, T. M., \& Kalbfleisch, P. J. (2000). Interracial dating: The implications of race for initiating a romantic relationship. The Howard Journal of Communications, 11, 49-64.

Herr, G. J. (2009). Factors influencing Black-White interracial marriage satisfaction (Doctoral dissertation). Retrieved from Proquest Theses and Dissertations.* 
Hohmann-Marriott, B., Amato, P. (2008). Relationship quality in interethnic marriages and cohabitations. Social Forces, 87(2), 825-855.*

Jackson, E. (2016). The sustainability of interracial couples' relationships in the midst of challenges and reactions from familial and societal contexts (Doctoral dissertation). Retrieved from ProQuest Dissertations Publishing. (Accession No. 3745472

Jansezian, K. (2000). Gender differences in perceived love, empathy, relationship satisfaction, family influence, and importance of money and material things among individuals in current dating or marital interracial or intraracial relationships (Doctoral dissertation). Retrieved from Proquest Theses and Dissertations (Accession No. 9984819).*

Johns, A.L., Newcomb, M.D., \& Bradbury, T.N. Alcohol-related problems, anger, and marital satisfaction in monoethnic Latino, biethnic Latino, and European American newlywed couples. Journal of Social and Personal Relationships, 24(2), 255-275.*

Karney, B. R., \& Bradbury, T. N. (1995). The longitudinal course of marital quality and stability: A review of theory, methods, and research. Psychological Bulletin, 118(1), 3.

Kohn, C. S. (2000). Risk factors for marital discord among interfaith and interracial couples (Thesis). Retrieved from Proquest Theses and Dissertations (Accession No. 9982764).*

La Taillade, J. J. (1999). Predictors of satisfaction and resiliency in African American/White interracial relationships (Doctoral Disertation). Retrieved from Proquest Theses and Dissertations (Accession No. 9952857).*

Lande, J. R. (2007). Interracial Asian Indian/European American couples: An exploration of gender role ideology, culture, and relationship satisfaction (Doctoral dissertation). Retrieved from Proquest Theses and Dissertations (Accession No. 3306479).* 
Lantsman, M. (2003). Relationship satisfaction as function of congruence of acculturation Levels and Ethnic Identification in Interracial Couples (Doctoral dissertation). Retrieved from Proquest Theses and Dissertations (Accession No. 3098118).*

Lee, S. (2013). Comparing marital satisfaction, acculturation, and personality across Asianmixed couples and Asian couples in the United States (Doctoral dissertation). Retrieved from Proquest Theses and Dissertations (Accession No. 3587932).*

Lewis, R., Yancey, G., \& Beltzer, S. (1997). Racial and non-racial factors that influence spouse choice in black/white marriages. Journal of Black Studies, 28(1), 60-78.

Loving v. Virginia, 388 U.S. 1 (1967)

Moher, D., Liberati, A., Tetzlaff, J., Altman, D. G. (2009). Preferred reporting items for systematic reviews and meta-analyses: the PRISMA statement. BMJ 2009, 339, b2535. doi: $10.1136 /$ bmj.b2535

Muller, R. D. (2004). Relationship dynamics in Latino-White Intercultural Marriages: a Three Group Comparison. Retrieved from Seton Hall University Dissertations and Theses (Accession No. 1411).*

Naratadam, T. J. (2005). Marital satisfaction related to acculturation and inter/interaracial aspects of Asian-Indian marriages (Doctoral dissertation). Retrieved from Proquest Theses and Dissertations (Accession No. 3259773).*

Negy, C., \& Snyder, D. K. (2000). Relationship satisfaction of Mexican American and nonHispanic White American interethnic couples: Issues of acculturation and clinical intervention. Journal of Marital and Family Therapy, 26(3), 293-304. doi:10.1111/j.1752-0606.2000.tb00299.x.* 
Pew Research Center. (2015). Intermarriage in the U.S. 50 years after Loving v. Virginia. Washington, D.C.

Pettigrew, T. F. Intergroup contact theory. Annual Review of Psychology, 49, 65-85. doi:10.1146/annurev.psych.49.1.65

Race. (n.d.) In Merriam-Webster's collegiate dictionary. Retrieved from http://www.merriamwebster.com/dictionary/race

Reiter, M. J. (2008). Communication and satisfaction in inter-and intraracial and inter-and intrafaith romantic relationships (Doctoral dissertation). Retrieved from Proquest Theses and Dissertations (Accession No. 3315749).*

Rosenblatt, P. C., Karis, T. A., \& Powell, R. D. (1995). Multiracial couples: Black \& White voices. Thousand Oaks, CA: Sage.

Shibazaki, K. \& Brennan, K. A. (1998). When birds of different feathers flock together: A preliminary comparison of intra-ethnic and inter-ethnic dating relationships. Journal of Social and Personal Relationships, 15(2), 248-256.

Stevenson, T. (1994). Comparing the relationships of interracial and same-race couples: Implications for providing couples therapy (Doctoral dissertation). Retrieved from Proquest Theses and Dissertations (Accession No. 9532958).*

Troy, A.B., Lewis-Smith, J., \& Laurenceau, J. (2006). Interracial and intraracial romantic relationships: The search for differences in satisfaction, conflict, and attachment style. Journal of Social and Personal Relationships, 23(1), 65-80.

doi:10.1177/0265407506060178

U.S. Census Bureau. (1970). Marital status (Report No. PC2-4C). Washington, DC: U.S. Government Printing Office. 
U.S. Census Bureau. (1980). Marital characteristics (Report No. PC80-2-4C). Washington, DC: U.S. Government Printing Office.

U.S. Census Bureau. (2010). Households and families (Report No. CB12-68). Washington, DC: U.S. Government Printing Office.

Wright, S. C., Aron, A., McLaughlin-Vople, T., Ropp, S. A. (1997). The extended contact effect: Knowledge of cross-group friendships and prejudice. Journal of Personality and Social Psychology, 73(1), 73-90.

$\mathrm{Wu}, \mathrm{K}$. The sweetness of forbidden fruit: Interracial daters view their partners more positively and report more positive regard from their partners (Thesis). Retrieved from Proquest Theses and Dissertations (Accession No. 1519514).*

Yancey, G., \& Yancey, S. (1998). Interracial dating: Evidence from personal advertisements. Journal of Family Issues, 19, 334-348.

Zhang, Y.,\&Van Hook, J. (2009).Marital dissolution among interracial couples. Journal of Marriage and Family, 71(1), 95-107. doi:10.1111/j.1741-3737.2008.00582.x.

*Included in meta-analysis 